\title{
Estimating the storage term in eddy covariance measurements: the ICOS methodology
}

\author{
Leonardo Montagnani ${ }^{1,2 *}$, Thomas Grünwald ${ }^{3}$, Andrew Kowalski ${ }^{4,5}$, Ivan Mammarella ${ }^{6}$, Lutz Merbold ${ }^{7,8}$, \\ Stefan Metzger ${ }^{9,10}$, Pavel Sedlák $k^{11,13}$, and Lukas Siebicke ${ }^{12}$
}

${ }^{1}$ Faculty of Science and Technology, Free University of Bolzano, Piazza Universitá 1, 39100 Bolzano, Italy

${ }^{2}$ Forest Services, Autonomous Province of Bolzano, Via Brennero 6, 39100 Bolzano, Italy

${ }^{3}$ Technical University Dresden, Institute of Hydrology and Meteorology, Tharandt, Germany

${ }^{4}$ Department of Applied Physics of the University of Granada, Granada, 18071, Spain

${ }^{5}$ Andalusian Centre for Environmental Research (CEAMA-IISTA), Granada, 18071, Spain

${ }^{6}$ Department of Physics, University of Helsinki, Helsinki, P.O. Box 68, 00014, Finland

${ }^{7}$ Mazingira Centre, International Livestock Research Institute (ILRI), PO Box 30709, 00100 Nairobi, Kenya

${ }^{8}$ Department of Environmental System Sciences, Institute of Agricultural Sciences, ETH Zurich, Universitaetsstrasse 2, 8092 Zurich, Switzerland

${ }^{9}$ National Ecological Observatory Network, Battelle, 1685 38th Street, Boulder, CO 80301, USA

${ }^{10}$ Department of Atmospheric and Oceanic Sciences, University of Wisconsin-Madison, 1225 West Dayton Street, Madison, WI 53706, USA

${ }^{11}$ Institute of Atmospheric Physics CAS, Bocni II 1401, 14131 Praha 4, Czech Republic

${ }^{12}$ University of Goettingen, Bioclimatology, Büsgenweg 2, 37077 Göttingen, Germany

${ }^{13}$ Department of Matter and Energy Fluxes, Global Change Research Institute, CAS, Bělidla 986/4a, 603 00, Brno, Czech Republic

Received December 31, 2017; accepted June 26, 2018

\begin{abstract}
In eddy covariance measurements, the storage flux represents the variation in time of the dry molar fraction of a given gas in the control volume representative of turbulent flux. Depending on the time scale considered, and on the height above ground of the measurements, it can either be a major component of the overall net ecosystem exchange or nearly negligible. Instrumental configuration and computational procedures must be optimized to measure this change at the time step used for the turbulent flux measurement. Three different configurations are suitable within the Integrated Carbon Observation System infrastructure for the storage flux determination: separate sampling, subsequent sampling and mixed sampling. These configurations have their own advantages and disadvantages, and must be carefully selected based on the specific features of the considered station. In this paper, guidelines about number and distribution of vertical and horizontal sampling points are given. Details about suitable instruments, sampling devices, and computational procedures for the quantification of the storage flux of different GHG gases are also provided.

Keywords: ICOS, protocol, storage flux, eddy covariance, greenhouse gases
\end{abstract}

*Corresponding author e-mail: leonardo.montagnani@unibz.it

\section{INTRODUCTION}

The eddy covariance (EC) technique to measure gas exchange between the biosphere and atmosphere is comonly applied under simplifying assumptions. In general, the turbulent flux represents most of the measurable exchange, at least under ideal site conditions. Among the other two components of the mass continuity equation (Eq. (5)), the advection flux proved to be not negligible in many cases, but hardly directly measurable at half-hourly time steps (Aubinet et al., 2010; Montagnani et al., 2010; Siebicke et al., 2012). But these caveats do not necessarily apply to the storage flux. Nevertheless, this component of the continuity equation is commonly neglected, or oversimplified by estimating it from a one-point measurement (Greco and Baldocchi, 1996; Hollinger et al., 1994).

The reason for the little historical attention paid to this flux component is probably linked to the initial predominant focus on the overall carbon budget as obtained by the EC technique (Desjardins, 1985; Grace et al., 1996), and to 
the negligible contribution of the storage term to the longterm budget (Baldocchi, 2008). This is particularly the case if a dataset is continuous and no or very few data are missing or removed for quality concerns.

More recently, interest in budgets of greenhouse gases (GHGs) other than carbon dioxide $\left(\mathrm{CO}_{2}\right)$ has increased. These GHGs such as methane $\left(\mathrm{CH}_{4}\right)$ and nitrous oxide $\left(\mathrm{N}_{2} \mathrm{O}\right)$ measured by the EC technique, show surface exchanges that are more complex than those of $\mathrm{CO}_{2}$ (Desai et al., 2015). In addition, the growing interest in using EC data to study functional relations with environmental variables, and the circumstance that both water vapour $\left(\mathrm{H}_{2} \mathrm{O}\right)$ and $\mathrm{CO}_{2}$ fluxes are strongly influenced by a marked daily pattern of the storage flux component, has led to a need for more accurate storage flux estimates.

Within the pan-European long-term research infrastructure ICOS (Integrated Carbon Observations System), it was decided that the storage flux be a mandatory measurement for ecosystem sites, similar to the turbulent flux. This decision focussed attention on the theoretical and practical aspects of measuring this flux. The literature overview of the measurements of the storage flux showed that little effort was made in the past in order to comprehensively formalize the definition of the variable itself, the setup needed for its quantification and the computations necessary for its determination. In most of the studies, the focus was given to the effect of the distribution in the vertical of the sampling points (Bjorkegren et al., 2015; Yang et al., 1999, 2007; Wang et al., 2016), with only a few notable efforts to investigate the effect of the sampling frequency (Finnigan, 2006; Heinesch et al., 2007). Only recently, and possibly motivated by the discussion leading to the formalization of the ICOS storage protocol, some new concepts were experimentally tested, like the relevance of horizontally distributed air sampling points (Nicolini et al., 2018) or were theoretically approached, such as the definition of the representative control volume (Metzger et al., 2018; Xu et al., 2018a).

The purpose of this publication, which reflects the current ICOS protocol and instructions, is to set a standard for measuring (i.e. instruments and infrastructure) and estimating the storage flux at half hourly time steps, and thus aims at improving the overall accuracy of the EC technique. The considered scalars comprise carbon dioxide, water vapour, methane and nitrous oxide. We will formalize the storage flux term of the continuity equation in the framework of the conservation of the dry molar fraction and we will describe guidelines for the measurement of variables required for the estimation of the storage flux between the ground and the level of EC measurement. Further, we will provide indications for the preparation of a set of standardised variables necessary for an automated storage flux determination as conducted within ICOS, and we will give guidelines for the storage flux computation.

\section{METHODOLOGY}

Description of the variable: formal derivation, definition and units

The storage term is the term in the conservation of mixing ratio equation related to the scalar $\left(\right.$ e.g. $\left.\mathrm{CO}_{2}\right)$ accumulation/depletion in an imaginary control volume centred at the EC flux tower. This volume, approximating the same temporal and spatial scales of its corresponding components of the continuity equation (i.e. EC turbulent flux) will be referred to as the storage volume.

Following Kowalski and Argüeso (2011), the boundarylayer budget equation for a scalar constituent is expressed in terms of conservation of the mixing ratio $(c)$, defined as the ratio of the density of the scalar $\left(\rho_{c}\right)$ to that of dry air $\left(\rho_{d}\right)$ and expressed in terms of mass. For consistency with turbulent flux measurements we will later scale the mixing ratio storage term by the molecular mass to yield a term with molar units.

From the quotient rule of calculus, we can write the material derivative of the mixing ratio $\frac{D c}{D t}$ in the atmosphere as:

$$
\frac{D c}{D t}=\frac{D\left(\rho_{c} / \rho_{d}\right)}{D t}=\frac{1}{\rho_{d}} \frac{D \rho_{c}}{D t}-\frac{\rho_{c}}{\rho_{d}^{2}} \frac{D \rho_{d}}{D t} .
$$

Neglecting molecular diffusion, all dry air constituents move at the same velocity, and so we can substitute into Eq. (1) the continuity equations for both the scalar of interest:

and dry air:

$$
\frac{D \rho_{c}}{D t}=-\rho_{c} \frac{\partial u_{i}}{\partial x_{i}},
$$

$$
\frac{D \rho_{d}}{D t}=-\rho_{d} \frac{\partial u_{i}}{\partial x_{i}},
$$

to demonstrate that there is no material change in the mixing ratio $\left(\frac{D c}{D t}=0\right)$ in air outside of the laminar sublayer. Expanding the material derivative into spatial and temporal variations, scaling by the dry air density $\left(\rho_{d}\right)$, and decomposing wind motions according to Reynolds averaging rules (overbars denote temporal averages and primes fluctuations around the mean), yields the continuity equation:

$$
\overline{\rho_{d}}\left(\frac{\partial \bar{c}}{\partial t}+\bar{u}_{i} \frac{\partial \bar{c}}{\partial x_{i}}+\frac{\partial}{\partial x_{i}}\left(\overline{u_{i}{ }^{\prime} c^{\prime}}\right)\right)=0,
$$

which in explicit form becomes:

$$
\frac{\overline{\rho_{d}} \partial \bar{c}}{\partial t}+\bar{u}_{i} \frac{\overline{\rho_{d}} \partial \bar{c}}{\partial x_{i}}+\frac{\overline{\rho_{d}} \partial}{\partial x_{i}}\left(\overline{u_{i}{ }^{\prime} c^{\prime}}\right)=0 .
$$

Of the three terms, the first is the storage term, the second is the advection term, and the third the turbulent flux term. In this formulation, the turbulent flux divergence is neglected.

The storage flux $J_{c}$ is then defined as the volume integral over the first term in Eq. (5), divided by the scalar molecular mass $M\left(e . g\right.$., $\mathrm{M}=0.018 \mathrm{~kg} \mathrm{~mol}^{-1}$ for $\left.\mathrm{CO}_{2}\right)$ : 


$$
J_{c}=\frac{1}{M} \int_{0}^{h} \overline{\rho_{d}}\left[\frac{1}{4 L^{2}} \int_{-L}^{+L} \frac{\delta \bar{c}}{\delta t} \delta x_{1} \delta x_{2}\right] \delta x_{3},
$$

where: $L$ is the half-length of a side of the Eulerian control volume (Finnigan et al., 2003; Leuning et al., 2008), $x_{1}, x_{2}$, are the axes defining the time mean velocity vector $\bar{u}$ and $x_{3}$ is the axis perpendicular to ${ }^{-}$. The vertical integration limits are the top of the laminar sublayer (lower boundary, which can be approximated to the ground level, 0) and the EC measurement height, $h$.

In order to quantify the storage flux, all of the spacetime terms in Eq. (6) should be measured. In the past, the storage flux measurement typically focused on the vertical tower column and not the control volume as a whole. To nevertheless permit a statement about $J_{\mathrm{c}}$ the control volume was assumed to be horizontally and vertically homogeneous (i.e. $\left.\partial / \partial x_{1}=0, \partial / \partial x_{2}=0\right)$ :

$$
J_{c}=\frac{1}{M} \int_{0}^{h} \frac{\overline{\rho_{d}}}{\delta c} \delta \frac{\delta}{\delta t} \delta
$$

However, real ecosystems are heterogeneous in many respects and on many scales, and Eq. (6) is thus no longer necessarily equal to Eq. (7). This spatial repetitiveness challenge (Nappo et al., 1982) is addressed in Sect. 'Spatial and temporal sampling design' (below). The matter is additionally aggravated by a representation challenge: for each time-step and measurement level the time-rate-of-change observations in Eq. (7) represent a different, mismatching Lagrangian source area (Raupach, 1988). Techniques to perform the necessary regularization are only recently emerging (Metzger, 2018; Xu et al., 2018b), and will be given consideration in future iterations of the ICOS data processing framework.

\section{Definition of considered gases and their flux sources}

The vast majority of carbon and a significant portion of water and nitrogen present in terrestrial ecosystems is stored in solid form (e.g. wood, grass) or in liquid form/ solution. These forms can significantly contribute to the long-term ecosystem exchange. However, for all the solid and liquid components and their exchanges see Saunders et al. (2018). We will limit our analysis to the gaseous component.

Variation in the dry molar fraction of a given gas in the air can be due to biological processes (e.g. photosynthesis, respiration, methanogenesis and denitrification) and physical processes (i.e. dew and fog formation, or gas-phase chemical reactions). Hence, the amount of trace gases and water vapour within an ecosystem control volume is not a conserved quantity, since a number of sinks/sources exist, particularly in the top soil layer (here we will use the top soil as a reference height for the processes taking place inside the soil) and at leaf level.

\section{Storage terms units}

Once air density and water vapour molar fraction are measured, the molar fraction of a given gas (i.e. $\mathrm{CO}_{2}$ ) can be expressed in mol mol${ }^{-1}$ of dry air. Sub-units ( $\mathrm{mmol}, \mu \mathrm{mol}$ and nmol) are convenient to express dry molar fractions of different gases. For consistency with eddy covariance and chamber data, it is convenient to express the fluxes (i.e. the variation in time in the air control volume, $J_{c}$ ) in terms of $\mathrm{mol} \mathrm{m} \mathrm{s}^{-2}$, with characteristic sub-units for specific gases, as listed in the Table 1.

If data are measured in mass units, they should be converted to molar units. The molecular masses of dry air, $\mathrm{CO}_{2}$, water vapour, $\mathrm{CH}_{4}$ and $\mathrm{N}_{2} \mathrm{O}$ are 28.964, 44.010, 18.015, 16.042 and $44.013 \mathrm{~g} \mathrm{~mol}^{-1}$, respectively. For instance, the mixing ratio of $\mathrm{CO}_{2}$ (mass $\mathrm{CO}_{2} /$ mass dry air) is equal to the molar fraction with respect to dry air multiplied by the ratio of molecular masses (44.010/28.965).

If gas concentration data are expressed as molar fraction in wet air, neglecting spectroscopic correction, they must be corrected for the dilution of water vapour. The water vapour diluted mole fraction, $c_{\text {wet }}$ and the dry gas mole fraction, $c_{d r y}$ of a scalar s $\left(i . e . \mathrm{CO}_{2}\right)$ are related by the following equation:

$$
\frac{c_{w e t}}{c_{d r y}}=1-0.01 H_{a c t},
$$

where $H_{a c t}$ is the actual $\mathrm{H}_{2} \mathrm{O}$ molar fraction (in \%) (Rella et al., 2013).

\section{Measurement methods and instrumentation}

The accuracy and precision of $J_{\mathrm{c}}$ depends on the characteristics of the analysers used including their calibration, the frequency and temporal distribution of the measurements, and finally their spatial distribution to characterize spatial variations within the control volume. To better characterize the spatial distribution of the scalar of interest, the need to take air samples both in the vertical and in the horizontal is foreseen.

Since the storage flux is defined as the time variation of the dry molar fraction of the scalar of interest in the control volume representative of the turbulent flux measurement, it follows that it has to be assessed and the sampling uncertainties have to be minimized both in time and in space. The instrumental set-up needed for the measurements must be optimized to give the best possible representation of the

Table 1. Units of measurement of storage fluxes of the considered gases

\begin{tabular}{lcc}
\hline Scalar & $\begin{array}{c}\text { Variable/ } \\
\text { components }\end{array}$ & Flux units \\
\hline $\mathrm{H}_{2} \mathrm{O}$ & $\mathrm{J}_{\mathrm{H}_{2} \mathrm{O}}$ & $\mathrm{mmol} \mathrm{m}^{-2} \mathrm{~s}^{-1}$ \\
$\mathrm{CO}_{2}$ & $\mathrm{~J}_{\mathrm{CO}_{2}}$ & $\mu \mathrm{mol} \mathrm{m}^{-2} \mathrm{~s}^{-1}$ \\
$\mathrm{CH}_{4}$ & $\mathrm{~J}_{\mathrm{CH}_{4}}$ & $\mathrm{nmol} \mathrm{m} \mathrm{s}^{-1}$ \\
$\mathrm{~N}_{2} \mathrm{O}$ & $\mathrm{J}_{\mathrm{N}_{2} \mathrm{O}}$ & $\mathrm{nmol} \mathrm{m} \mathrm{s}^{-1}$ \\
\hline
\end{tabular}


spatial variability of the average dry molar fraction in the control volume, and the temporal sampling should approximate the dry molar fraction at the beginning and at the end of the measurement period.

Concerning the spatial representativeness, it is well established that increasing the number of samples in the vertical would increase the accuracy of the measurements (de Araujo et al. 2010; Yang et al., 2007). Only recently has the problem been recognized of horizontal spatial representativeness of the whole volume from which the fluxes originate, and different solutions based on a single analyser with ramified air intakes (Marcolla et al., 2014) or multiple analysers (Siebicke et al., 2011) were tested. If the variability in dry molar fraction were random, we could assume that the standard error $\varepsilon$ of the true average spatial dry molar fraction value would follow the relation:

$$
\varepsilon=\frac{1}{\sqrt{N}},
$$

where: $N$ is the number of sample points. Since this distribution is frequently non-isotropic, the sampling scheme would be optimized if the sampling is larger where the variability is higher (generally near the ground).

Concerning the frequency of the measurements, Finnigan (2006) showed that replacing the instantaneous profiles measured at the beginning and at the end of the measurement period with half-hour averages can give storage estimates which are significantly biased (underestimation). Heinesch et al. (2007) pointed out that the error induced by low sampling frequency was reduced with increasing the number of samplings in the half-hour. The typical frequency of the signal in the air was generally not considered in storage flux measurements (but see Cescatti et $a l ., 2016)$ and the system designs generally did not respect the Nyquist-Shannon sampling theorem, which states that the sampling frequency should be at least twice the maximal frequency of the measured signal. Although further research is needed on this argument, we can assume that the sampling error tied to inadequate sampling frequency will similarly follow the general rule of Eq. (9) until the Nyquist-Shannon limit, above which a further decrease in $\varepsilon$ is negligible.

The constraint given by the sampling theorem has a relevant consequence for the sampling design. If trace gas molar density in free air is measured, the frequency of the gas sampling should comprise all relevant motions, a requirement which similarly applies to EC systems, and if sampling frequency is lower, air receivers acting as low-pass filters have to be placed along the sampling line.

Once measurements have been performed without aliasing, a proper time interval of data selection for the storage flux computation has to be established. At present, conclusive indications for an optimal time interval are not available, however Finnigan (2006) suggested the use of smoothed concentration values in time windows from 100 to
$200 \mathrm{~s}$ depending on the degree of turbulence development, with larger sampling windows in case of lower turbulence. We therefore recommend recording the available dry molar density values at $1 \mathrm{~Hz}$, to allow for different computation algorithms. We recommend computing averages over intervals from 60 to $300 \mathrm{~s}$. Since a maximum of additional $300 \mathrm{~s}$ will be used for interpolation purposes, at least $1200 \mathrm{~s}$ in the half hour are not used for storage flux computation. It is convenient, however, that all the data measured during the half-hour are collected, also in consideration of possible future changes in the computational procedure. The residual measurement capacity of the analyser(s) can be used, if necessary, for other uses, like chamber measurements. This is particularly economically advantageous for expensive analysers, like those for $\mathrm{CH}_{4}$ and $\mathrm{N}_{2} \mathrm{O}$ measurements.

\section{Sampling configurations}

Three different configurations are currently accepted within ICOS

\section{Configuration 'A'.}

In configuration 'A' or 'separate sampling' scalar molar densities at each individual height are continuously sampled by an individual gas analyser that is dedicated to a single height only. Closed or enclosed path analysers could be used to quantify the mixing ratio or the dry molar density. Open path analysers suffer from problems related to surface window contamination with consequent insufficient precision, and are therefore not recommended for the external use for which they are conceived, in the long term ICOS perspective. Enclosed and closed-path analysers can be installed at sampling height with short tubing or situated in a common location using longer tubing. In the latter case, the air representing the selected height is conveyed along the different lines to the dedicated analyser. The different lines are measured continuously. It should be assured to have the same tubing length for each sampling line to achieve simultaneous measurements at individual heights. If closed path analysers are used, as in Siebicke et al. (2011), additional values of temperature and pressure in the free air should be collected.

Inter-analyser calibration requirements are set by the specific application: while measurements of vertical profiles/vertical distributions of trace gases require careful inter-calibration of all gas analysers involved, the pure computation of the storage flux term does not rely on concentration differences between individual gas analysers, thus relaxing calibration requirements. Instead, analysers need to be stable over time, complying with specific accuracy and $30 \mathrm{~min}$ drift requirements (specified below).

\section{Configuration ' $\mathrm{B}$ '}

In configuration ' $\mathrm{B}$ ' or 'sequential sampling' a single gas analyser is used to measure the scalar molar densities from all heights (sampling points). The gas concentration is averaged in an air receiver before being measured (Yi et 
al., 2000), acting as a low-pass filter and reducing the high frequencies composing the signal in the frequency domain. In this configuration, the sampling rate is determined by the measurement repetition of the same air intake point in the half hour. Excessive smoothing of the signal should be avoided. We suggest as a convenient time for mean air volume change in the air receiver and the tubing system twice the time needed to complete a measurement cycle, hence between 1.5 and $10 \mathrm{~min}$, although further analysis is needed on this issue. Three way solenoid (or rotary) valves can be used to switch the air from one line to the next, and repetition of the measurement series (full profile sampling) should be hence between 60 and $300 \mathrm{~s}$. Measurements can be performed within as little as a few minutes during the time intervals containing the beginning and the end of the half-hour and should be related to the associated half hour EC measurement.

\section{Configuration ' $\mathrm{C}$ '.}

Sampling scheme 'C' or 'mixed sampling' deploys a single gas analyser to continuously sample in parallel air from all the points along a vertical profile. Air from individual heights, sampled through individual lines, is then blended together in a single mixing volume before entering the gas analyser. This provides a vertically integrated air sample. In order to account for the specific vertical extents of individual layers for which individual air intakes are representative, the amount of sample from any respective height entering the mixing volume needs to be proportional to the vertical extent of the given layer. The uneven thickness of the vertical layers results in the requirement of a wide range of mass flow rates entering the mixing volume. In practical configurations the range of mass flow rates across all lines is typically so large that the different flow rates are impractical regarding the typical length of tubing required to feed samples from distributed locations to a central analyser unit, as either the maximum flow rates cannot be achieved or the minimum flow rates would lead to unacceptable sample travel times. Therefore, all lines need to be continuously flushed with constant and identical flow rates. These lines are then continuously subsampled close to the gas analyser using line specific mass flow rates which are proportional to the respective vertical layer thickness. This setup requires two pumps, one for the line flushing and one for the proportional mixing and sample delivery into the analyser.

Mass flow control of individual sampling lines can be performed through individual controllers at each line, with either manual or automatic flow rate control. Typical suitable manual flow controllers include rotameters and automatic flow controllers with thermal mass flow controllers (MFC).

While above options are acceptable, a third flow control option is preferred for its automatic control, long-term stability and cost efficiency. This tailored option (cur- rently under development at the University of Goettingen, Germany) consists of a single automatic flow control unit (FCU) serving multiple channels, provides long-term consistency of flow rates through continuous automatic control and is more cost effective than individual MFCs. This flow control unit (FCU) can be deployed in height-proportional flow rate mode as required for measurement scheme $\mathrm{C}$ or in sequential mode as required for measurement scheme $\mathrm{B}$.

Technical specifications of the recommended sampling systems

In sampling scheme ' $A$ ', the air representing the selected height is conveyed along the different lines to the analysers devoted to the sampling of the air. The different lines
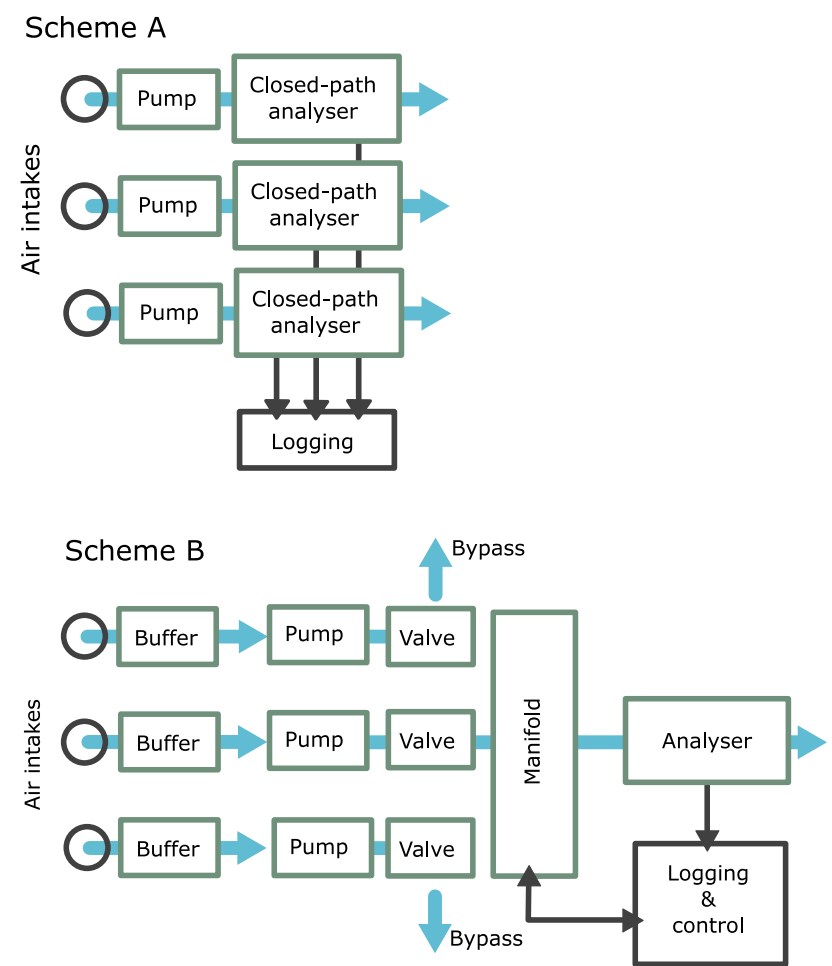

Scheme C

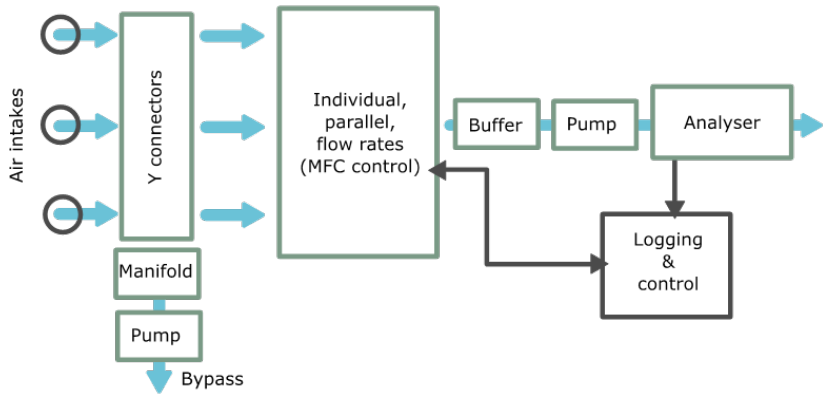

Fig. 1. Schematic of storage profile measurement setup options. Scheme 'A', separate sampling; scheme 'B', sequential sampling; scheme ' $\mathrm{C}$ ', mixed sampling. Variants employing enclosed path analyser and different pump configurations (e.g. 2 pumps) are also possible. Blue lines and arrows represent air flow directions, black lines and arrows electrical connections and data transfer. 
are measured continuously. Since analysers are temperature sensitive, care should be exercised in order to minimize the variability of analysers' temperature (particularly with laser absorption spectrometers to measure $\mathrm{CH}_{4}$ and $\mathrm{N}_{2} \mathrm{O}$ ).

In sampling scheme ' $\mathrm{B}$ ', a single gas analyser characterizes the profile system based on a given number of sampling lines reaching selected heights above the ground. Sampling has to be done continuously and a companion variable will indicate the active line, if any. The system to be used to sample the air can consist of two pumps $\left(\approx 15 \mathrm{~L} \mathrm{~min}^{-1}\right.$ flow, Feigenwinter et al., 2008), one for collecting air and one for sampling, or of a set of small-medium sized pumps $(\approx 8-10 \mathrm{~L}$ $\mathrm{min}^{-1}$ ), each sampling a different line, having one air intake (or multiple, see below). To limit the problem of leakage in the profile system (e.g. at the level of the manifold, flowmeters, connectors, filters, etc.), the pump could be located between the sampling line and the manifold if possible (e.g. not with laser spectrometers, which require partial vacuum in the sample cell). In this way the system operates above ambient pressure and therefore any eventual leak does not contaminate the measurements, since the leakage flow would be directed outward. Diaphragm pumps with brushless motors should be used in this configuration. This is mainly to avoid pump debris in the sampling system and rapidly blocked filters. In addition, by placing the analyser at the end of the line, the pressure in the cell is independent of the pressure in the lines since the cell outlet is open to ambient pressure. This design (Marcolla et al., 2014) minimizes pressure fluctuations induced by the pumps and the difference in pressure between lines, thus reducing one of the sources of uncertainty in profile measurements reported by Heinesch et al. (2007).

Recommended size of mixing volumes ranges from 3 to $30 \mathrm{~L}$ (min-max 2-50 L), and the flow rate should be set between 1 and $5 \mathrm{~L} \mathrm{~min}^{-1}$, with $5 \%$ maximum difference among lines. With the commonly used inner tube diameter of $4 \mathrm{~mm}$, flow rates larger than $\approx 4.5 \mathrm{~L} \mathrm{~min}^{-1}$ are not practically recommended due to the rapidly increasing resistance to the air flow along the tube. For fast switching between the sampling lines, a larger tube inner diameter is recommended (M. Mölder, personal communication). A measurement cycle will be completed within $300 \mathrm{~s}$. Manual or automatic flow regulators will be used to maintain constant flow at each sampling line and regular checks need to be noted in a field-book or recorded in digital format.

A separate digital flow meter has to be used to record the flow in the sampling line in case of using manual flow regulators without sensing and recording capabilities. Alternatively, automatic MFCs can be used. Flow data for each line have to be collected together with molar density, temperature and cell pressure at $1 \mathrm{~Hz}$ frequency. Threeway or rotary valves should be used to select the line to be sampled. Switching time between lines will depend on tube inner diameter and length, on air sampling flow rate and on the analyser response time for the selected gas.
Time response for water vapour is higher than for $\mathrm{CO}_{2}$ and smaller for $\mathrm{CH}_{4}$ and $\mathrm{N}_{2} \mathrm{O}$. The tubes should be inert to the sampled gases; e.g. teflon, polyethylene and stainless steel are adequate materials. The final section of the tubing system, close to the analyser, should be kept at a temperature at least $3^{\circ} \mathrm{C}$ higher than ambient air temperature to avoid condensation inside the tubing, and the heating of all the tubing system is recommended where possible. Each air intake should be protected by a rain-cap and by a filter. Filters similar to those used for turbulent exchange measurements are recommended (Swagelock) or disc filters with $2 \mu \mathrm{m}$ pore size (e.g. Gelman, PTFE or similar).

\section{Auxiliary measurements}

Air temperature profile

An air temperature profile complements the tower instrumentation set-up. The profile will be composed of aspirated and screened temperature sensors. We recommend that sensors be placed at the same heights as the air intakes and be held $1.5 \mathrm{~m}$ away from the tower, using supporting material, typically rigid booms, with a maximum cross sectional area of $46 \mathrm{~cm}^{2}$ or less to avoid the direct effect of the tower structure.

Recommended instruments will be shaded and ventilated PT100 or PT1000 thermistors for air temperature. Relative humidity sensors are also recommended to complement the set-up, and should be of the same type as the sensor used at the turbulent flux measurement level. All sensors will therefore have the same accuracy and precision.

\section{Pressure sensor}

For the scope of the storage flux computation, an ordinary pressure sensor used among the meteorological variables to define the air pressure will be used. Equations 17-19 (see below), or their linear approximation, will be used to extend the measured value to the different heights. The pressure measured inside the analyser cell, being influenced by the pump pressure, cannot be used for the storage flux computation.

\section{Instrument specifications}

\section{$\mathrm{CO}_{2}$}

Since the primary objective of the storage term computation is to achieve an improved quantification of NEE, a similar accuracy/precision as the one requested for turbulent flux computation has to be achieved. Dry mole fraction has to be measured in the range 320-900 $\mu \mathrm{mol} \mathrm{CO}_{2} \mathrm{~mol}^{-1}$ (which can reach even higher values in some cases, up to $1500 \mu \mathrm{mol} \mathrm{CO} \mathrm{mol}^{-1}$ ), accuracy $\leq \pm 0.5 \mu \mathrm{mol} \mathrm{CO} \mathrm{mol}^{-1}$ (max. drift over $30 \mathrm{~min}$ ), precision $\leq \pm 1.6 \mu \mathrm{mol} \mathrm{CO} \mathrm{mol}^{-1}$ at $1 \mathrm{~Hz}$ or $\pm 0.5 \mu \mathrm{mol} \mathrm{CO} \mathrm{Col}^{-1}$ at $0.1 \mathrm{~Hz}$ assuming a post-processing signal integration of $10 \mathrm{~s}$ (in case option B is chosen). In option B, typical gas response (rise-fall 
10-90, 90-10\%) should be $\leq 5 \mathrm{~s}$ (assuming $5 \mathrm{~s}$ purge time). In options $\mathrm{A}$ and $\mathrm{C} 10 \mathrm{~s}$ is sufficient for similar rise and fall rates.

\section{$\mathrm{H}_{2} \mathrm{O}$}

The sensors employed should have the capacity to also measure water vapour $\left(\mathrm{H}_{2} \mathrm{O}\right)$. Accuracy and precision of water vapour measurements have to be proportional to those of $\mathrm{CO}_{2}$ and other gases (accuracy $\leq \pm 0.1 \%$, precision $\leq \pm 0.1 \%$, see Rella et al. (2013) for further details). Also similar should be the typical gas response time.

$$
\mathrm{CH}_{4} \text { and } \mathrm{N}_{2} \mathrm{O}
$$

Sensors that are capable of measuring dry molar fractions of $\mathrm{CH}_{4}$ and $\mathrm{N}_{2} \mathrm{O}$ with adequate accuracy, precision and response time remain limited. Fast response analysers such as laser absorption spectrometers are essential to measure fluxes of $\mathrm{CH}_{4}$ and $\mathrm{N}_{2} \mathrm{O}$ with the eddy covariance technique. If the flux measurements are complemented by storage flux measurements, the use of the same or similar instruments is recommended (Table 2), although response time characteristics are less demanding in case of storage flux measurements.

Several assumptions are made and criteria have to be fulfilled before setting up storage flux measurements at ICOS ecosystem stations: (1) considerable $\mathrm{CH}_{4}$ or $\mathrm{N}_{2} \mathrm{O}$ fluxes and (2) storage fluxes are per se only needed for tall canopies (e.g. forests, tree plantations etc.).

The time response needed will depend on the selected configuration, option B being the most demanding in terms of response time, while at the same time being the most commonly applied technique (due to financial restrictions in maintaining several laser systems per station). Overall, each instrument must have the capacity to also measure water vapour $\left(\mathrm{H}_{2} \mathrm{O}\right)$ in order to derive dry mole fractions.

\section{Air temperature}

Based on the sensitivity analysis (see below), relatively large accuracy errors are tolerable in temperature measurements. However, temporal stability must be quite good to avoid significant errors. The specified temporal stability error of $1.5^{\circ} \mathrm{C}$ will be easily achieved by thermistors. However, environmental contamination of the temperature signal could result in errors of this magnitude for nonaspirated systems. Aspirated, shielded temperature sensors should be employed. The use of platinum resistance thermometers (PRTs) is recommended because of their long term stability.

\section{Air pressure}

In case instruments measuring the dry molar ratio only are used, air pressure ( $p$, expressed in Pascal, $\mathrm{Pa}$ ) has to be measured together with air temperature to determine the dry molar volumetric density $(n)$, according to the ideal gas law:

$$
p V=n R T,
$$

where: $V$ is the air volume $\left(\mathrm{m}^{3}\right), n$ is the number of moles of dry air, $R$ is the universal gas constant $\left(R=8.314 \mathrm{~J} \mathrm{~K}^{-1} \mathrm{~mol}^{-1}\right)$ and $T$ is the air temperature $(\mathrm{K})$. Pressure can be measured at a single location.

\section{Accuracy and precision}

The accuracy and precision requested for the measurement of the specified gases is reported in Table 3 .

Results of a sensitivity analysis are reported in Table 4.

The values in Table 4 indicate measurement errors that sum to an $11 \%$ error when estimating the $\mathrm{CO}_{2}$ storage flux for the given set of measurements. It is notable that errors in the mean values must be an order of magnitude larger than typical sensor accuracy and likely spatial variability in order to obtain an $11 \%$ error in the storage term.

\begin{tabular}{|c|c|c|c|}
\hline Model & Manufacturer & Gas species & Resolution $(\mathrm{Hz})$ \\
\hline LI-7200 & Li-Cor Biosciences & $\mathrm{CO}_{2}, \mathrm{H}_{2} \mathrm{O}$ & 20 \\
\hline LI-7000 & Li-Cor Biosciences & $\mathrm{CO}_{2}, \mathrm{H}_{2} \mathrm{O}$ & 20 \\
\hline LI-840 & Li-Cor Biosciences & $\mathrm{CO}_{2}, \mathrm{H}_{2} \mathrm{O}$ & 1 \\
\hline $\mathrm{EC} 155$ & Campbell Scientific & $\mathrm{CO}_{2}, \mathrm{H}_{2} \mathrm{O}$ & 10 \\
\hline Mini QCL, Dual QCL & Aerodyne Research & $\mathrm{CH}_{4}, \mathrm{~N}_{2} \mathrm{O}, \mathrm{H}_{2} \mathrm{O}$ or $\mathrm{CH}_{4}, \mathrm{~N}_{2} \mathrm{O}, \mathrm{H}_{2} \mathrm{O}$ and $\mathrm{CO}_{2}$ & $\begin{array}{c}10 \\
\text { depending } \\
\text { on configuration }\end{array}$ \\
\hline G2301; G2401 & Picarro & $\mathrm{CH}_{4}, \mathrm{CO}_{2}, \mathrm{H}_{2} \mathrm{O}$ & 0.2 \\
\hline G2508 & Picarro & $\mathrm{CH}_{4}, \mathrm{~N}_{2} \mathrm{O}, \mathrm{CO}_{2}, \mathrm{H}_{2} \mathrm{O}$ & 10 \\
\hline $\mathrm{LGR} \mathrm{CH}_{4} / \mathrm{N}_{2} \mathrm{O}$ analyser & Los Gatos Research & $\mathrm{CH}_{4}, \mathrm{~N}_{2} \mathrm{O}, \mathrm{H}_{2} \mathrm{O}$ & 10 \\
\hline LGR 911-0010 & Los Gatos Research & $\mathrm{CH}_{4}, \mathrm{CO}_{2}, \mathrm{H}_{2} \mathrm{O}$ & $\geq 10$ \\
\hline TG200A & Campbell Scientific & $\mathrm{CO}_{2} \mathrm{CH}_{4}, \mathrm{~N}_{2} \mathrm{O}$ depending on configuration & \\
\hline
\end{tabular}

Table 2. Potential analysers to measure of $\mathrm{CO}_{2}, \mathrm{H}_{2} \mathrm{O}, \mathrm{CH}_{4}$, and $\mathrm{N}_{2} \mathrm{O}$ concentrations 


\section{Spatial and temporal sampling design}

Spatial sampling strategy: vertical locations

A defined number of measurement points have to be placed along the vertical as a function of the eddy covariance measurement height. The number of points should be increased in case of complex (non-monotonic) profiles of gas concentrations. It is also stipulated that any distinguishable canopy layer must be represented in the sampling scheme. In order to give a general indication of the minimal number, $N$, of sampling points in the vertical of a tower with eddy covariance instruments placed at the height $h$, in meters, the following equation can be used as guideline:

$$
N=\left\lfloor\left(h^{a}\right)\right\rfloor,
$$

where: $\left\lfloor\left(h^{a}\right)\right\rfloor$ represents the integer part of a given value. The default value for the exponent $\alpha$ is 0.667 .

This means e.g. that three sampling points profile is needed for an eddy covariance measurement height of 6 $\mathrm{m}, 7$ points for $20 \mathrm{~m}$, and 10 points for a $35 \mathrm{~m}$. In case of documented regular vertical profiles of the gas of interest, the value of the exponent $\alpha$ can be reduced to 0.5 . A profile is defined as regular in the absence of a distinguishable canopy layer and/or if the $N=\left\lfloor h^{0.5}\right\rfloor$ sampling and $N=\left\lfloor h^{0.667}\right\rfloor$ sampling lead to storage flux not differing by more than $10 \%$ in more than $10 \%$ of the cases.

In case of configuration $\mathrm{B}$, a number of vertical points exceeding that given by $N=\left\lfloor h^{0.75}\right\rfloor$ is not recommended, since higher vertical densities could result in reduced sampling repetitions. The measurement of a single point should last approximately $15 \mathrm{~s}$, even under an optimal system construction, and the first $5 \mathrm{~s}$ of each measurement have to be discarded in order to avoid contamination of the current measurement by the previous one (Marcolla et al., 2014). Since the maximum repetition time is $300 \mathrm{~s}$, the maximum

Table 3. Accuracy and precision requirements

\begin{tabular}{cll}
\hline Storage flux & Accuracy & Precision \\
\hline $\mathrm{H}_{2} \mathrm{O}$ & $+/-1 \mathrm{mmol} \mathrm{m}^{-2} \mathrm{~s}^{-1}$ & $+/-1 \mathrm{mmol} \mathrm{m}^{-2} \mathrm{~s}^{-1}$ \\
$\mathrm{CO}_{2}$ & $+/-1 \mu \mathrm{mol} \mathrm{m} \mathrm{s}^{-1}$ & $+/-1 \mu \mathrm{mol} \mathrm{m} \mathrm{s}^{-1}$ \\
$\mathrm{CH}_{4}$ & $+/-1 \mathrm{nmol} \mathrm{m}^{-2} \mathrm{~s}^{-1}$ & $+/-1 \mathrm{nmol} \mathrm{m}^{-2} \mathrm{~s}^{-1}$ \\
$\mathrm{~N}_{2} \mathrm{O}$ & $+/-1 \mathrm{nmol} \mathrm{m}^{-2} \mathrm{~s}^{-1}$ & $+/-1 \mathrm{nmol} \mathrm{m}^{-2} \mathrm{~s}^{-1}$ \\
\hline
\end{tabular}

number of lines is 20 in case of $15 \mathrm{~s}$ measurement period, or lower if the time needed for stabilization of each channel is longer. This implies that configuration ' $\mathrm{B}$ ' is not recommended for storage flux computation in the case of high towers, complex profiles and slow switching systems. In such cases, configuration ' $\mathrm{C}$ ' is preferable.

The recommended number and vertical distribution of sampling points imply that the simple computation of the storage value as obtained from a single point, such as the eddy covariance measurement point (Greco and Baldocchi, 1996) can be acceptable (representing a special case of configuration ' $A$ ') only if the turbulent flux is measured at a low height above the ground $(<2 \mathrm{~m}$, or up to $4 \mathrm{~m}$ in case of documented, regular, vertical distribution of molar densities, and negligible horizontal variability).

The vertical distribution of measurement points should be adapted to specific site conditions. If specific features in the vertical distribution of molar densities do not suggest other distribution of sensors, it is recommended to use a profile's vertical sensor distribution corresponding to:

$$
z_{N_{i}}=\left(N_{i}^{b} h\right) N^{-b}
$$

where $z_{N_{i}}$ is the height of the sampling point in meters, $N_{i}$ is the number of the air intake point ( $N_{i}=1$ is the lowest), $\mathrm{h}$ is the height of the sonic anemometer and $N$ is the number of sampling points, as defined by Eq. (11). The recommended sampling points distribution is dependent on the exponent $b$, whose default value is 1.5 , and which can be set between 1 (linear distribution, to be used when the molar densities of the scalar of interest are linearly changing along the vertical) and 2.718 (logarithmic distribution, to be used when the molar densities decrease logarithmically with height above ground).

Example: Given a tower height of $10 \mathrm{~m}$ the setup can be composed by 4 air sampling points, tubes with $4 \mathrm{~mm}$ inner diameter, flow rate of $4 \mathrm{~L} \mathrm{~min}^{-1}$, sampling time of $15 \mathrm{~s}(5 \mathrm{~s}$ purging and $10 \mathrm{~s}$ reading) and an analyser such as Li-7000 (Li-Cor, Lincoln, NE, USA). The repetition period will be $60 \mathrm{~s}$ and the air receiver will have a volume of 8-10 L. Two or four pumps can be used depending on the configuration. A 3-way solenoid valve manifold (or rotary valves) will be used for line selection. A commercial datalogger (such as CR 1000, Campbell Scientific Inc., USA) can be used to automatically provide the input for the line switching

Table 4. Errors in directly measured variables which sum to a relative error in the flux storage estimate of $<20 \%$

\begin{tabular}{llll}
\hline Variable & Reference value & Typical sensor error & Relative sensor error \\
\hline Gas constant in dry air, $R_{d}$ & $287.06 \mathrm{~J} \mathrm{~kg}^{-1} \mathrm{~K}^{-1}$ & $0.01 \mathrm{~J} \mathrm{~kg}^{-1} \mathrm{~K}^{-1}$ & $<0.01 \%$ \\
Air temperature, $T$ & $288 \mathrm{~K}$ & $0.3 \mathrm{~K}$ & $0.1 \%$ \\
Time interval, $\delta t$ & $1800 \mathrm{~s}$ & $0.1 \mathrm{~s}$ & $<0.01 \%$ \\
Air intake height, $h$ & $10 \mathrm{~m}$ & $0.1 \mathrm{~m}$ & $1 \%$ \\
Dry air partial pressure, $p_{d}$ & $100 \mathrm{kPa}$ & $20 \mathrm{~Pa}$ & $0.02 \%$ \\
Variation in dry mole density, $\rho_{c}$ & $2.4 \mu \mathrm{mol} \mathrm{mol}^{-1}$ & $0.2 \mu \mathrm{mol} \mathrm{mol}^{-1}$ & $10 \%$ \\
\hline
\end{tabular}

Examples given for $\mathrm{CO}_{2}$. 
and for sampling the data (Marcolla et al., 2014). In case laser absorption spectrometers are used, data can be saved directly on the computer or fed into a datalogger collecting the additional variables.

\section{Spatial sampling strategy: horizontal locations}

Large horizontal differences in $\mathrm{CO}_{2}$ molar densities can occur under specific meteorological conditions, even in supposedly homogeneous forests (Feigenwinter et al., 2008 and Aubinet et al., 2010), and not only at advection-prone sites (Etzold et al., 2010; Montagnani et al., 2009). Even larger horizontal differences are expected for $\mathrm{CH}_{4}$ and $\mathrm{N}_{2} \mathrm{O}$ due to the typical marked spatial variability of their sources and sinks.

This implies the need of considering the horizontal distribution of the molar density to properly represent the reference volume. The horizontal variability is expected to be highest at the lowest levels, because of the spatial variability of GHG's sources/sinks at the surface (Acosta et al., 2013), combined with heterogeneity in the drag force exercised by canopies and the possible interaction with below-canopy wind circulation (Yang et al., 2007).

To take into account the horizontal variability in the scalars' dry molar density, when the vertical sampling points are $\geq 3$, a minimum of four air inlets, spaced at least $5 \mathrm{~m}$ apart around the tower are prescribed at the lowest level, and two at the second level, while at higher levels one air inlet is considered to be sufficient (Nicolini et al., 2018). In forests where the canopy radius is larger than $5 \mathrm{~m}$, also the sampling points should have larger horizontal spacing.

A ramified design of the sampling system is recommended, with horizontal tube branching obtained by $\mathrm{T}$ connectors, since it assures homogeneity of the pressure inside the tubing (Marcolla et al., 2014). The sampled air collected at the same height above ground level is then mixed in a single intake buffer volume representing a given height level. Ramification should be designed to maintain an equal tube length between sampling points and to equally distribute the flow between all the branches.

\section{Temporal sampling strategy}

Scalar changes in the air control volume may occur over a wide range of time scales. The storage change flux typically integrates to zero at long time scales because the mean change of the dry mole fraction of scalars over diel and annual cycles is roughly zero. However, at shorter time scales, such as the typical 30 min integration time of turbulent flux measurements (Lenschow et al., 1994), the storage term can be a significant portion of the scalar flux.

In configuration ' $A$ ', if buffer volumes are not used, a sampling frequency identical to that for the turbulent fluxes is recommended $(\geq 10 \mathrm{~Hz})$ and $1 \mathrm{~Hz}$ average values have to be recorded. This can be achieved using the internal instrument software, where available. In configuration 'B', although the effective sampling frequency of each line will be determined by the discontinuous sampling in the range between 0.01 and $0.003 \mathrm{~Hz}$, a continuous time-series at a rate of $1 \mathrm{~Hz}$ should be recorded, including periods belonging to the central part of the half-hour, not used for storage flux computation. In configuration ' $C$ ', if a small mixing volume is used, sampling and recording should be both at $1 \mathrm{~Hz}$. In all configurations, companion variables (temperature, pressure, channel number, flow rate) should be collected and averaged at the same $1 \mathrm{~Hz}$ frequency.

\section{Final dataset and storage flux computation}

\section{Discretisation of the storage flux equation}

The objective of measurement, computation and modelling of dry mole densities is to achieve an adequate estimate of the mean values of the scalar of interest in the reference volume at the beginning and at the end of the computational period (typically $1800 \mathrm{~s}$ ) to compute the variation in time as storage flux. To achieve this, it can be convenient to have an estimate of the vertical and horizontal variability.

For computational purposes it is convenient that storage flux $J_{c}$ (Eq. (6)) of a scalar of interest $c$ is written, after discretisation, as:

$$
J_{c}=\sum_{i=1}^{N} \overline{\rho_{d_{i}}}\left(\frac{\Delta c}{\Delta t}\right)_{i} \Delta z_{i}
$$

where $\overline{\rho_{d_{i}}}$ is the time-averaged dry air density in the layer representative of the individual measurement point, $i$, $(\Delta c / \Delta t)_{i}$ is the scalar mole density difference at height $i$ over a time period $\Delta t, \Delta z_{i}$ is the vertical extent of the corresponding $i$ th air layer (i.e. vertical segment), and $N$ is the number of segments.

Vertical integration of the storage term requires integration limits, i.e. boundaries separating individual vertical layers for which storage measurements are taken. The height above ground of any one layer boundary $\left(z l_{i}\right)$ will be defined as the mean height of the gas measurement level below and above the boundary:

$$
z l_{i}=\frac{\left(z_{N_{i}}+z_{N_{i+1}}\right)}{2} .
$$

Note that for a non-equidistant distribution of measurement heights, the measurement is not centered relative to the boundaries of the layer. Rather, using Eq. (12), the measurement level is closer to the lower boundary, taking into account the typically preferential vertical concentration distribution of $\mathrm{CO}_{2}$ and other considered gases. Exceptions to Eq. (14) are the height of the lower-most vertical layer boundary that will be at the ground surface $\left(z l_{0}=0\right)$ and the upper most boundary, which will coincide with the upper air intake point and with the height $h$ (where $z l_{n}=h$ ) of the turbulent flux measurements.

The vertical segments that appear in Eq. (13) are then defined as:

$$
\Delta z_{i}=z l_{i}-z l_{i-1} .
$$

Instead of $\overline{\rho_{d_{i}}}$ for individual layers, the average dry air density $\left(\overline{\rho_{d}}\right)$ for the air column can be used as a scaling 
variable to convert the kinematic storage term into a massbased quantity:

$$
J_{c}=\overline{\rho_{d}} \sum_{i=1}^{N}\left(\frac{\Delta c}{\Delta t}\right)_{i} \Delta z_{i} .
$$

For this purpose, measurements are needed that allow the determination of the air pressure, humidity, and temperature. The average air temperature $(\bar{T})$ of the air control volume must be determined. For this purpose, a temperature measurement at every air intake height of the storage profile is sufficient, and $\bar{T}$ can be calculated as the average of temperatures measured along the profile. The average will be weighted by the depths of the air layers which are represented by the individual measurement points (Eq. (15)). This allows calculation of the atmospheric scale height $(\mathrm{H})$ of the air in the tower column as:

$$
H=\frac{R_{d} \bar{T}}{g},
$$

with the average air temperature $(\bar{T})$ as above (in units of $\mathrm{K})$, and required constants include both the particular gas constant for dry air $\left(R_{d}=287.06 \mathrm{~J} \mathrm{~kg}^{-1} \mathrm{~K}^{-1}\right)$ and the gravitational acceleration $\left(g=9.8 \mathrm{~m} \mathrm{~s}^{-2}\right)$.

The average air pressure $(\bar{p})$ is also required. For this, it is sufficient to measure the pressure at the surface $\left(p_{0}\right)$, and take advantage of the near exponential decrease in pressure with height, according to:

$$
p=p_{0} e^{-\frac{z}{H}} .
$$

From this, the average (in time and space) pressure can be determined from a simple linear approximation of Eq. (18), so that:

$$
\bar{p}=p_{0}\left(1-\frac{0.5 z}{H}\right),
$$

where: $z$ is the turbulent flux measurement height. For the towers of limited height as ordinarily used in eddy covariance measurements $(<100 \mathrm{~m})$, the computed value of pressure decrease with elevation can be further approximated to $10 \mathrm{~Pa} \mathrm{~m}^{-1}$.

The average vapour pressure $(\bar{e})$ is also required. This can be determined, in a way similar to $\bar{T}$ as the weighted average of the water vapour measurements.

From these data, the average dry air pressure $\left(\overline{p_{d}}\right)$ can be calculated as the difference of observed total air pressure and water vapour pressure, $\bar{p}-\bar{e}$, according to Dalton's law.

Finally, applying the ideal gas law, the average dry air density can be determined as:

$$
\overline{\rho_{d}}=\frac{\overline{p_{d}}}{R_{d} \bar{T}} .
$$

Analogically, dry air density $\overline{\rho_{d_{i}}}$ for each individual layer in Eq. (20) is given by:

$$
\overline{\rho_{d_{i}}}=\frac{p_{d_{i}}}{R_{d} \overline{T_{i}}},
$$

with $p_{d_{i}}=p_{i}-\bar{e}_{i}$ and $p_{i}$ obtained from Eq. (18) for $z=z_{i}$ or from Eq. (19) for $0.5 z=z_{i}$.

When the sampling configuration ' $\mathrm{C}$ ' is used, the storage flux, $J_{c}$ will be calculated simply as:

$$
J_{c}=\overline{\rho_{d}} \frac{\Delta c}{\Delta t} h .
$$

\section{Spatial interpolation procedure}

Although different interpolation schemes and modelling algorithms can be used to obtain the vertical distribution of the considered scalar, we can rely on a regular and relatively dense sampling scheme and we aim at formulating a consistent computational algorithm for all the sampling schemes. Therefore, we recommend the rectangular interpolation of $\Delta z_{i}$, segments, as defined by Eq. (15), based on $c_{i}$ values representative of the segment. In the case of configuration ' $C$ ', the flow of the different channels of the MFC will be set to be proportional to the depth of the sampled vertical segment $\Delta z_{i}$.

In other words, the top measurement level at the height of the eddy covariance sonic anemometer, $z_{n}=h$ will be considered as representative of the highest segment, while other segments will be computed considering an intermediate measurement value taken along the segment.

Example: A tower (eddy covariance measurement height $h=10 \mathrm{~m}$ ) with four vertical sampling locations (Eq. (11)), which are distributed according to the default value of the exponent in Eq. (12) (which is 1.5), will have the air sampling heights at $1.25,3.54,6.50$, and $10 \mathrm{~m}$. The four $\Delta z_{i}$ segments will be $\Delta z_{1}=0.00-2.39 \mathrm{~m}, \Delta z_{2}=2.39-5.02 \mathrm{~m}$, $\Delta z_{3}=5.02-8.25 \mathrm{~m}$ and $\Delta z_{4}=8.25-10 \mathrm{~m}$ (Eq. (14)). This interpolation procedure can be used for all the possible configurations, including type ' $C$ ', where flow rates for the different levels have to be regulated proportionally to the vertical width of the $\Delta z_{1}$ segments. In case of configuration ' $C$ ', in this example, the air sampling flow $\left(\mathrm{L} \mathrm{min}^{-1}\right)$ at the different levels will be set to be proportional to $1.75,2.39,2.62$ and 3.23 for $\Delta z_{1}, \Delta z_{2}, \Delta z_{3}$ and $\Delta z_{4}$, respectively (Eq. (15)).

Temporal discretization, interpolation and integration

Following Finnigan (2006) we should avoid that storage flux estimates be influenced by single eddies penetrating inside the canopy, and we should use for the storage flux computation a period long enough to capture an adequate number of these eddies to avoid introducing bias to the profiles or single observational points. As a rule of thumb, the integration period can be taken equal to $10 \tau$, where $\tau$ is the integral time scale of turbulent time series. Given the wide differences in the turbulent characteristics existing at the ICOS ecosystem stations, and lacking adequate experimental evidence for all site conditions, we consider an adequate time of integration $10 \tau$ a period between 60 and $300 \mathrm{~s}$, with the shorter integration time to be reserved to 
turbulent conditions as observed in short canopies, $300 \mathrm{~s}$ to be reserved for dense canopies of $30 \mathrm{~m}$ or above, and $180 \mathrm{~s}$ as default value. This integration period in which the average dry molar fraction $\bar{C}$ will be calculated, will be applied to all the storage configurations ('A', 'B', 'C'), although the low-pass filtering obtained through the use of air receivers, when present, will limit the practical relevance of this averaging procedure.

While in case of configuration ' $\mathrm{A}$ ' and ' $\mathrm{C}$ ' measured values at $1 \mathrm{~Hz}$ are readily available, in configuration ' $\mathrm{B}$ ' only discontinuous measurements will be available. It is therefore recommended that the values for the different heights representative of the selected time interval be obtained from linear interpolation between consecutive measurements. This means that a maximum of additional $300 \mathrm{~s}$ in the half-hour should be reserved to obtain a molar fraction $(C)$ representing a given height and a given time. To make the temporal interpolation, the average of 5-15 s of dry molar fraction data, measured after channel change and stabilization, will be used as an input data.

Example: Assuming that turbulent flux and storage flux estimates are to be computed for timestamps 08:00:00, then by convention the 08:00:00 timestamp represents the flux corresponding to observations between 07:30:00 and 08:00:00. Assuming a $10 \tau$ value of $180 \mathrm{~s}, \Delta c$ will then be computed from the time average of measurements from 07:58:31 to 08:01:30 minus the time average of measurements from 07:28:30 to 07:31:30.

To synchronize storage flux and eddy covariance measurements, the average time employed by the sampled air from the air intake to the analyser will be calculated based on flow rate and air volume of the sampling system; timestamps will be adjusted accordingly.

\section{Computational procedure for air density values}

It is convenient that the time averaged and vertically averaged values of dry air density $\rho_{d_{i}}$ be computed in the same way as for the scalar $C$ from available measurements of air temperature, relative humidity and pressure.

List of variables needed for the storage flux computation

Within ICOS, storage flux calculations will be done centrally by the ICOS Ecosystem thematic Centre (ETC). The following variables are needed for the computation of the storage flux: Time ( $1 \mathrm{~s}$ resolution); measurement level; trace gas species $\left(\mathrm{CO}_{2}, \mathrm{H}_{2} \mathrm{O}, \mathrm{CH}_{4}\right.$ or $\left.\mathrm{N}_{2} \mathrm{O}\right)$; gas analyser temperature $(\mathrm{K})$ and pressure $(\mathrm{Pa})$; flow rate $\left(\mathrm{L} \mathrm{min}^{-1}\right)$; trace gas concentration in wet air $\left(\mathrm{mol} \mathrm{mol}^{-1}\right)$; water vapour concentration $\left(\mathrm{mol} \mathrm{mol}^{-1}\right)$, although a relaxed sampling frequency of $0.033 \mathrm{~Hz}$ is acceptable to be consistent with other meteorological variables acquisition frequency.

For the correct computation of the storage flux, the additional metadata reported in the Table 5 should be also recorded. The number of sample points (as obtained from
Eq. (11)) and the eventual establishment of profile system for tower heights between 2 and $4 \mathrm{~m}$ will be defined after profile testing. Profiles have to be measured during peak vegetation development and daily air temperature higher than the 25th percentile of local annual range. Measurements have to be done both during daytime in neutral or instable conditions and during night time in stable conditions, for a total of at least $48 \mathrm{~h}$. A system having multiple gas analysers (option ' $A$ ') will be used for testing purposes. Collected data have to be sent to the ETC for evaluation. These documentation measurements should be repeated in case of significant changes of the ecosystem to be measured (including canopy height) which might affect the profile, e.g. cultivation of maize if the existing documentation was for a wheat canopy.

It is necessary that information about tube inner diameter, tube length, flow rate and size of mixing volume be provided (Table 5) and it is recommended that the time employed by the sampled air from the air intake to the analyser be calculated by flowing artificial gases at known, higher than ambient concentration through the tubing. Such testing should last long enough to determine the time constant in the mixing volumes when present.

The establishment of the profile measurements is foreseen between 2 and $4 \mathrm{~m}$ when $J_{c}$ fluxes calculated on the basis of 3 measured points diverge by at least $10 \%$ from those obtained from a single measurement point in at least $10 \%$ of the data during the testing. Irrespective of tower height, it is foreseen that if the system, due to inadequate configuration or technical quality, will not attain the characteristics required according to the abovementioned criterion of $10 \%$ difference, it will be changed with another system to meet the needed level of accuracy, precision and long-term stability.

\section{Profile testing and documentation}

The recommended presence of temperature and humidity sensors, together with a single air pressure sensor and the use of Eq. (18) or (19), will make feasible the computation of the dry air density and the cross check between

Table 5. List of metadata to be recorded for each sampling level

\begin{tabular}{lll}
\hline & Variable & Units \\
\hline sensor model & Text \\
sensor ID & alphanumeric \\
sample flow rate & $\mathrm{L} \mathrm{min}^{-1}$ \\
Trace gas & intake length & $\mathrm{m}$ \\
& intake inner diameter & $\mathrm{mm}$ \\
& intake material & Text \\
& buffer volume size & $\mathrm{L}$ \\
& & \\
& height above surface & $\mathrm{m}$ \\
Sample point & easting (UTM) & $\mathrm{m}$ \\
& northing (UTM) & $\mathrm{m}$ \\
\hline
\end{tabular}


water vapour concentrations measured by infrared gas analysers (IRGAs) and/or laser absorption spectrometers and meteorological sensors. Measured values of RH can be converted to water vapour mole density $\left(\chi_{\mathrm{H}_{2} \mathrm{O}}\right)$ according to the approximate solution of the Clapeyron-Clausius equation:

$$
\frac{d p}{d T}=\frac{\lambda}{T\left(V_{b}-V_{a}\right)},
$$

where: $p$ is pressure, $\lambda$ is the latent heat of vaporization, and $V$ is the volume of the two phases $a$ and $b$, can be made explicit and approximated:

$$
\begin{gathered}
\chi_{\mathrm{H}_{2} \mathrm{O}}=(6088.484 \exp (t /(t+237.6429) 17.31303) / \\
18.0153) R H) /(p /(8.314(t+273.15)),
\end{gathered}
$$

where: $R H$ is the fraction of humidity relative to dew point, $t$ is the air temperature expressed in degrees Celsius, and $p$ the air pressure expressed in Pascal.

\section{Calibration and maintenance}

Testing and eventual calibration of gas sensors will follow the same guidelines as for the turbulent flux analyser. Sensors for companion variables ( $\mathrm{P}, \mathrm{T}$, flow rate) should be tested with the same frequency.

\section{Leakage testing}

Leakage testing should be performed at the same frequency and in the same occurrences as for calibration. Gases having a defined mixing ratio will be flowed through the different lines and the measured value will be in the range of $\pm 1 \%$ with respect to the gas nominal value. In case configuration $\mathrm{C}$ is adopted, the testing will be done separately for all lines.

\section{Scheduled replacement}

Factory calibration of the analyser(s) should be done with the same frequency as for the turbulent flux analyser. Extraordinary replacement should be done in case of malfunctioning (e.g. drift in measured molar densities). Tubing system should be checked annually and should be replaced at least every 10 years to avoid increasing rates of absorption / emission of measured gases along the tube. Expected pump lifetime is 2 years.

\section{RESULTS AND DISCUSSION}

\section{Biological and physical variables influencing the storage flux}

Similarly to the turbulent flux, the storage flux is proportional to plant and biological activity of the observed ecosystem, but it is also influenced by physical variables, partly different from those influencing the turbulent flux. Among the biological activities, the processes taking place at soil level, namely microbial, mycorrhizal and root respiration, methanogenesis in case of $\mathrm{CH}_{4}$ and nitrate reducing bacteria in case of $\mathrm{N}_{2} \mathrm{O}$, are particularly relevant. These biological variables are influenced by a combination of factors, like the substrate availability, water content and temperature.

The physical processes leading to accumulation of carbon dioxide in the surface air layer are mostly the same leading to the establishment of the turbulent flux (wind velocity, friction velocity, the vertical thermal gradient), but acting in the opposing direction: when these variables are large, the storage flux is in general minimal and the turbulent flux represents most of the gas exchange. Exceptions are the conditions of very strong winds leading to recirculation inside the canopy (Kutter et al., 2017; Xu et al., 2018b), and the morning transition period, when the gases stored in the lowest air layer tend to be removed from the considered ecosystem. At some sites, advection can also reduce the storage flux. Therefore, conditions with very low levels of turbulence, associated with a non-negligible below canopy wind velocity, can determine an advection increase and a reduction in the amount of biologically produced gases in the lowest air layer (McHugh et al., 2017). But the physical variable mostly influencing the measured storage flux at the eddy covariance sites is probably the simplest: the height above the soil where sonic anemometer and the gas analyser are placed. This is for the trivial reason that the storage flux is proportional to the amount of accumulated gas (or depleted, if negative), and it depends on the height of the air layer where it is measured.

\section{Temporal variability of molar densities}

Observed patterns of the storage flux for the different gases

Since the storage flux is a component of the equation describing the net ecosystem exchange of any GHG (Eq. (5)), it could be expected that its range is somewhat proportional to the overall flux. However, during the day, storage fluxes of the considered gases show a different pattern from that of the turbulent flux. Driven by changes in radiation, in soil moisture availability and also affected by ventilation within the canopy, the $\mathrm{CO}_{2}$ storage flux generally shows negative values in the morning, related to the decrease in molar densities in the air column, and positive values in the evening, when the opposite process of accumulation occurs (Aubinet et al., 2005). The $\mathrm{H}_{2} \mathrm{O}$ storage flux generally follows an opposite daily pattern. Methane and nitrous oxide behave more variably and are strongly dependent on the overall production/consumption rate as well as the ecosystem under observation. These gases may be characterized by diurnal cycles too, but not consistently throughout the year. Their diurnal cycles are either characterized by low emissions during night and morning and rising emissions during the day, or vice-versa.

In its daily pattern, the storage flux represents the first derivative of the equation representing the molar density of the considered gas. Since carbon dioxide and methane generally show a maximum in molar density at night, 
opposite to that of water vapour, it is expected that the diel pattern of the storage flux of these gases is also substantially different.

\section{Carbon dioxide:}

As reported by Baldocchi (2008), storage of $\mathrm{CO}_{2}$ is typically small during the day and on windy nights. However, significant positive values may be observed during poor mixing conditions at night when the $\mathrm{CO}_{2}$ produced by the ecosystem respiration is accumulating within and below the canopy. A negative peak of storage is often observed in the morning when nocturnally accumulated $\mathrm{CO}_{2}$ is flushed out of the ecosystem or absorbed by ecosystem assimilation (Goulden et al., 1996; Grace et al., 1996).

\section{Water vapour:}

For water vapour, given the positive correlation existing between water vapour saturation pressure and temperature, higher molar density values are generally observed in summer, during daytime, and near the ground. Following Baldocchi (2008) we can observe that storage of water vapour is small at night, the ecosystem transpiration rate being low during this period. Since during the day atmospheric conditions are unfavourable for the accumulation of any gases, the relevance of the water vapour storage flux is generally low. Water vapour storage flux shows a daily pattern generally positive at dawn and negative starting from the morning to noon.

\section{Methane:}

At present, published data about methane storage fluxes are scarce (Desai et al., 2015; Peltola et al., 2015). For tall towers, reported values of $\mathrm{CH}_{4}$ storage flux were on the same order of magnitude as the turbulent flux at night. The daily pattern is similar to what is observed for $\mathrm{CO}_{2}$, with negative values in the morning and positive ones later in the day and in the night. The positive peak frequently observed for $\mathrm{CO}_{2}$ in the evening is not evident. Horizontal variation in gas concentrations becomes even more important considering the patchiness of hotspots of $\mathrm{CH}_{4}$ and $\mathrm{N}_{2} \mathrm{O}$ production, particularly in grazed and agricultural systems.

\section{Observed value range of storage fluxes}

The range of storage flux is dependent on the height of the representative air column where measurements are conducted and on the variation in time of molar densities. Maximal values of storage fluxes can be assumed to be \pm 30 $\mu \mathrm{mol} \mathrm{CO} \mathrm{Cm}^{-2} \mathrm{~s}^{-1}$ and $\pm 5 \mathrm{mmol} \mathrm{H}_{2} \mathrm{O} \mathrm{m}^{-2} \mathrm{~s}^{-1}$. Relative variations are greater for $\mathrm{CH}_{4}$ and $\mathrm{N}_{2} \mathrm{O}$, with large storage fluxes during few events depending on the source strength and small variations during non-pulsed background emissions.

Observed ranges in the storage fluxes in different ecosystems are reported in Table 6. At the time of writing this paper, no information on typical $\mathrm{N}_{2} \mathrm{O}$ storage fluxes was available.

Considerations on the spatial and temporal

requirements of storage flux measurements as obtained in previous analyses

Different degrees of attention were given in the past to the three main sources of variability in the storage flux computation, i.e. the vertical and horizontal variability and the temporal variability in the scalar quantity.

Vertical variability received some attention (Yang et al., 1999), and several studies aimed at defining the best vertical distribution of the sampling points (Nicolini et al., 2018; Wang et al., 2016; Yang et al., 2007). In the vertical, the largest observed $\mathrm{CO}_{2}$ values and variations in dry molar density were observed at night in the first few meters above the ground, although with differences from site to site in the shape of the vertical profile. Secondary minima were found at the canopy level during daytime.

Table 6. Ranges in the storage fluxes observed in different ecosystem types

\begin{tabular}{|c|c|c|c|c|}
\hline Flux units & Study & Ecosystem & Height (m) & Range \\
\hline \multirow{2}{*}{$\mathrm{H}_{2} \mathrm{O}\left(\mathrm{mmol} \mathrm{m}^{-2} \mathrm{~s}^{-1}\right)$} & Haverd et al. (2007)* & Forest & 40 & -0.23 to $1.15 \mathrm{mmol} \mathrm{m}^{-2} \mathrm{~s}^{-1}$ \\
\hline & Ohkubo and Kosugi (2008)* & Temperate forest & 29 & -0.09 to $0.23 \mathrm{mmol} \mathrm{m}^{-2} \mathrm{~s}^{-1}$ \\
\hline \multirow{8}{*}{$\mathrm{CO}_{2}\left(\mu \mathrm{mol} \mathrm{m} \mathrm{s}^{-2} \mathrm{~s}^{-1}\right)$} & Al-Saidi et al. (2009) & Sorghum, Sugarcane & 6 & $+/-0.05 \mu \mathrm{mol} \mathrm{m} \mathrm{m}^{-2} \mathrm{~s}^{-1}$ \\
\hline & de Araujo et al. (2010) & Tropical forest & 30 & -20 to $10 \mu \mathrm{mol} \mathrm{m} \mathrm{m}^{-2} \mathrm{~s}^{-1}$ \\
\hline & Crawford et al. (2011) & Sub-urban & 45 & -2 to $3 \mu \mathrm{mol} \mathrm{m} \mathrm{m}^{-2} \mathrm{~s}^{-1}$ \\
\hline & Feigenwinter et al. (2008) & Three temperate forests & ca. 30 & -3 to $3 \mu \mathrm{mol} \mathrm{m}{ }^{-2} \mathrm{~s}^{-1}$ \\
\hline & Goulden et al. (1996) & Tropical forest & 30 & -12 to $7 \mu \mathrm{mol} \mathrm{m} \mathrm{m}^{-2} \mathrm{~s}^{-1}$ \\
\hline & Gu et al. (2012) & Temperate forest & 32 & -2 to $2 \mu \mathrm{mol} \mathrm{m} \mathrm{m}^{-2} \mathrm{~s}^{-1}$ \\
\hline & Ohkubo and Kosugi (2008) & Temperate forest & 29 & -3 to $2 \mu \mathrm{mol} \mathrm{m} \mathrm{m}^{-2}$ \\
\hline & Mammarella et al. (2007) & Boreal forest & 23 & -2 to $2 \mu \mathrm{mol} \mathrm{m} \mathrm{m}^{-2} \mathrm{~s}^{-1}$ \\
\hline \multirow{4}{*}{$\mathrm{CH}_{4}\left(\mathrm{nmol} \mathrm{m}^{-2} \mathrm{~s}^{-1}\right)$} & Desai et al. (2015) & Boreal landscape & 122 & -10 to $5 \mathrm{nmol} \mathrm{m}^{-2} \mathrm{~s}^{-1}$ \\
\hline & Peltola et al. (2015) & Temperate peatland & 6 & -2 to $2 \mathrm{nmol} \mathrm{m}^{-2} \mathrm{~s}^{-1}$ \\
\hline & Peltola et al. (2015) & Temperate peatland & 20 & -5 to $5 \mathrm{nmol} \mathrm{m}^{-2} \mathrm{~s}^{-1}$ \\
\hline & Peltola et al. (2015) & Temperate peatland & 60 & -11 to $15 \mathrm{nmol} \mathrm{m}^{-2} \mathrm{~s}^{-1}$ \\
\hline
\end{tabular}

*Original values expressed as latent heat $\left(\mathrm{W} \mathrm{m}^{-2}\right)$. 
The problem related to horizontal representativeness was ignored until recently (Marcolla et al., 2014; Metzger, 2018; Nicolini et al., 2018). Despite the assumption of horizontal homogeneity underlying the principles of eddy covariance technique, most flux measurement sites have some degree of horizontal heterogeneity in the topographic or biological surface. Air movements in conditions of low turbulence, which are frequent at night, further complicate the distribution of horizontal concentrations. This led to the recommendation of placing horizontal sampling points in addition to the vertical profile. This indication was experimentally confirmed by Nicolini et al. (2018).

Temporal variability was seldom considered (Finnigan, 2006; Heinesch et al., 2007) and not linked with the requirements imposed by the Nyquist-Shannon theory of sampling. The effect of the buffer volumes on measured molar densities was treated by Cescatti et al. (2016), although not specifically related to the storage flux computation.

\section{Selecting the sampling scheme}

The three possible configurations that can be used to measure the storage flux have both advantages and disadvantages, which can influence the selection at a given station.

Configuration ' $\mathrm{A}$ ' has the main advantage of the limited work needed for the installation, but tends to be more expensive due to the cost of the analysers, particularly if large variability exists in the vertical profile shape and in the horizontal, requiring several observational points. Different analysers need also adequate inter-calibration. This configuration can be the best solution to measure $J_{c}$ over short canopies, like grasslands, if $\mathrm{N}_{2} \mathrm{O}$ and $\mathrm{CH}_{4}$ measurements are not envisaged. Particularly economically convenient is the special case in which a single point is sufficient, because of the short and homogeneous air volume to be measured, so the instrument used for eddy covariance measurements can give also the requested values needed for the storage computation. Since this configuration provides the most comprehensive amount of information, it is foreseen as the reference during the phase of testing and evaluation.

Conversely, the time and costs required to build the setup to measure $J_{c}$ with configuration 'B' varies little with the number of sample points requested, so it is preferable with respect to configuration 'A' for measuring $J_{c}$ in high canopies such as forests, where, however, configuration ' $\mathrm{C}$ ' is theoretically preferable.

Configuration ' $\mathrm{C}$ ' is the easiest to implement once a reliable multi-intake mass-flow controller is available. Depending on the cost of the mass-flow controller, configuration ' $\mathrm{C}$ ' may also be the least expensive. The main drawback is that information on vertical distribution of mole densities is not obtained, but this is not strictly related to the storage flux computation. This setup, however, has the advantage of continuously measuring all heights without gaps in the observation (like in scheme B), without the need for sampling line changes which can introduce instabilities, e.g. due to pressure transitions (like in scheme B), while being at the same time more resource efficient than scheme A, requiring only a single gas analyser. Switching between individual sampling lines is not needed and if the analyser has an adequate sampling frequency the air receiver is needed only to assure thorough air mixing.

Given the inherent difficulties in the maintenance of the sampling scheme A with multiple analysers and adequate calibration, and the temporal resolution of configuration 'B' possibly limiting also accuracy and precision of the computed storage flux, our recommendation for the long term perspective of the ICOS infrastructure is to adopt sampling scheme ' $\mathrm{C}$ ', while it remains possible to use the other two configurations, particularly since additional information can be achieved with these more traditional setups. A careful analysis of site conditions and of fixed and variable costs of the selected configuration is recommended before installation.

\section{Cautions and limitations of the storage term} implementation

Yang et al. (1999) observed that the high variability in measured $\mathrm{CO}_{2}$ storage flux values, computed along vertical distributed sampling points, prevented its direct use in combination with the turbulent flux measurements. We assume that this information is overcome if the technical requirements developed in this paper are respected in the preparation and the maintenance of the needed setup. Nevertheless, care must be exercised when summing the measured storage values to the measured turbulent flux. A reason for caution is the possibility of a significant advection term, since the storage term and the advection term could cancel out under some atmospheric conditions. Considering that a reliable method to directly measure the advection term is currently not envisaged (Aubinet et al., 2010) the addition of the storage term would worsen the estimate of the ecosystem gas exchange in these particular conditions.

\section{CONCLUSIONS}

1. The analyses of the theoretical properties of the storage flux term, of the observed spatial distribution of the molar fractions in several published studies, and of the characteristics of the sampling schemes and infrastructures, all highlight the differences in requirements needed for the storage flux determination with respect to what is traditional in profile measurement of scalars gradients.

2. In particular, the sampled data should be representative of the spatial and temporal variability of the considered scalar $\left(\mathrm{CO}_{2}, \mathrm{H}_{2} \mathrm{O}, \mathrm{CH}_{4}\right.$ or $\left.\mathrm{N}_{2} \mathrm{O}\right)$ in the control volume over the fetch for the turbulent flux measured by eddy covariance. 
3. Three different set-ups can be used for the storage flux determination, each with its advantages and disadvantages, which make them adaptable to a range of site conditions and instruments availability.

4. The provided guidelines for sampling in time and space conduce the standardization of the data sampling and collection, and the reduction of the previously observed scatter in the measured storage flux values, largely attributable to inadequate sampling.

5. The storage flux measurement can be performed at the same time step as the turbulent flux measurements, adding accuracy in the quantification of the daily pattern of sources and sinks of greenhouse gases at ecosystem level.

6. Within the ICOS research infrastructure, it is necessary to achieve a methodological standardization of the relevant variables, and quantitative assessment of all the variables of interest. Based on their increasing relevance with EC system elevation above ground, measurements of the storage flux are mandatory where the EC system is placed at a height of $4 \mathrm{~m}$ or above. They are either mandatory or only recommended for tower height between 2 and $4 \mathrm{~m}$, depending on the storage flux relevance at the considered station.

Conflict of interest: The Authors declare no conflict of interest.

\section{ACKNOWLEDGEMENTS}

The National Ecological Observatory Network is a project sponsored by the National Science Foundation and managed under cooperative agreement by Battelle Ecology, Inc. This material is based upon work supported by the National Science Foundation (grant DBI-0752017, 2008-2018). Any opinions, findings, and conclusions or recommendations expressed in this material are those of the authors and do not necessarily reflect the views of the National Science Foundation.

\section{REFERENCES}

Acosta M., Pavelka M., Montagnani L., Kutsch W., Lindroth A., Juszczak R., and Janouš D., 2013. Soil surface $\mathrm{CO}_{2}$ efflux measurements in Norway spruce forests. Comparison between four different sites across Europe - from boreal to alpine forest. Geoderma, 192, 295-303. DOI: 10.1016/j. geoderma.2012.08.027.

Al-Saidi A., FukuzawaY. , Furukawa N., Ueno M., Baba S., and Kawamitsu Y., 2009. A system for the measurement of vertical gradients of $\mathrm{CO}_{2}, \mathrm{H}_{2} \mathrm{O}$ and air temperature within and above the canopy of plant. Plant Prod. Sci., 12(2), $139-149$.

de Araujo A.C., Dolman A.J., Waterloo M.J., Gash J.H.C., Kruijt B., Zanchi F.B., de Lange J.M.E. et al., 2010. The spatial variability of $\mathrm{CO}_{2}$ storage and the interpretation of eddy covariance fluxes in central Amazonia. Agricultural and Forest Meteorology, 150, 226-237.

Aubinet M., Berbigier P., Bernhofer Ch., Cescatti A., Feigenwinter C., Granier A., Grünwald Th., Havrankovà
K., Heinesch B., Longdoz B., Marcolla B., Montagnani L., and Sedlak P., 2005. Comparing $\mathrm{CO}_{2}$ storage and advection conditions at night at different CARBOEUROFLUX sites. Boundary Layer Meteorology, 116: 63-94. DOI: 10.1007/ s10546-004-7091-8.

Aubinet M., Feigenwinter C., Bernhofer Ch., Canepa E., Lindroth L., Montagnani C., Rebmann P., Sedlak E., and Van Gorsel A., 2010. Direct advection measurements do not help to solve the nighttime $\mathrm{CO}_{2}$ closure problem: Evidence from three different forests. Agricultural and Forest Meteorology, DOI:10.1016/j.agrformet.2010. 01.016.

Baldocchi D.D., 2008. 'Breathing' of the terrestrial biosphere: Lessons learned from a global network of carbon dioxide flux measurement systems. Turner Review. Australian J. Botany. https://doi.org/10.1071/BT07151.

Bjorkegren A.B., Grimmond C.S.B., Kotthaus S., and Malamud B.D., 2015. $\mathrm{CO}_{2}$ emission estimation in the urban environment: Measurement of the $\mathrm{CO}_{2}$ storage term. Atmos. Environ., 122, 775-790, doi:10.1016/j.atmosenv. 2015.10.012,

Cescatti A., Marcolla B., Goded I., and Gruening C., 2016. Optimal use of buffer volumes for the measurement of atmospheric gas concentration in multi-point systems. Atmospheric Measurement Techniques, 9(9): 4665-4672.

Crawford B., Grimmond C.S.B., and Christen A., 2011. Five years of carbon dioxide fluxes measurements in a highly vegetated suburban area. Atmospheric Environ., 45, 896905, doi:10.1016/j.atmosenv.2010.11.017.

Desai A., Xu K., Tian H., Weishampel P., Thom J., Baumann D., Andrews A.E., Cook B.D., King J.Y., and Kolka R., 2015. Landscape-level terrestrial methane flux observed from a very tall tower. Agric. Forest Meteorol., 201 (2015) 61-75.

Desjardins R.L., 1985. Carbon dioxide budget of maize. Agric. For. Meteorol., 36: 29-41.

Etzold S., Buchmann N., and Eugster W., 2010. Contribution of advection to the carbon budget measured by eddy covariance at a steep mountain slope forest in Switzerland. Biogeosciences, 7, 2461-2475, doi:10.5194/bg-7-24612010.

Feigenwinter Ch., Bernhofer Ch., Eichelmann U., Heinesch B., Hertel M., Janous D., Kolle O., Lagergren F., Lindroth A., Minerbi S., Moderow U., Mölder M., Montagnani L., Queck R., Rebmann C., Vestin P., Yernaux M., Zeri M., Ziegler W., and Aubinet M., 2008. Comparison of horizontal and vertical advective $\mathrm{CO}_{2}$ fluxes at three forest sites. Agric. Forest Meteor., 148, 12-24. DOI: 10.1016/j.agrformet.2007.08.013.

Finnigan J., Clement R., Mahli Y., Leuning R., and Cleugh A., 2003. A re-evaluation of long-term flux measurement techniques Part I: Averaging and coordinate rotation. Boundary-Layer Meteorology, DOI: 10.1023/A: 1021554900225

Finnigan J.J., 2006. The storage term in eddy flux calculations. Agric. For. Meteorol., 136, 108-113, doi:10.1016/j. agrformet.2004.12.010.

Goulden M., Munger J.W., Fan S.-M., Daube B.C., Wofsy S.C., 1996. Measurements of carbon sequestration by longterm eddy covariance: methods and a critical evaluation of accuracy. Global Change Biology, 2(3), 169-182, DOI: 10.1111/j.1365-2486.1996.tb00070.x. 
Grace J., Malhi Y., Lloyd J., McIntyre J., Miranda A.C., Meir P., and Miranda H.S., 1996. The use of eddy covariance to infer the net carbon dioxide uptake of Brazilian rain forest. Glob. Change Biol., 2, 209-217, doi:10.1111/j.1365-2486. 1996.tb00073.x

Greco S. and Baldocchi D., 1996. Seasonal variations of $\mathrm{CO}_{2}$ and water vapour exchange rates over a temperate deciduous forest. Global Change Biol., 2(3), 183-197.

Gu L., Massman W.J., Leuning R., Pallardy S.G., Meyers T., Hanson P.J., Riggs J.S., Hosmand K.P., and Yang B., 2012. The fundamental equation of eddy covariance and its application in flux measurements. Agric. Forest Meteorol., 152, 135-148, doi:10.1016/j.agrformet.2011.09.014.

Haverd V., Cuntz M., Leuning R., and Keith H., 2007. Air and biomass heat storage fluxes in a forest canopy: Calculation within a soil vegetation atmosphere transfer model. Agric. Forest Meteorol., 147, 125-139, doi: 10.1016/j.agrformet. 2007.07.006.

Heinesch B., Yernaux M., and Aubinet M., 2007. Some methodological questions concerning advection measurements: a case study. Boundary-Layer Meteor. 122, 457-478.

Hollinger D.Y., Kelliher F.M., Byers J.N., Hunt J.E., McSeveny T.M., and Weir P.L., 1994. Carbon dioxide exchange between an undisturbed old-growth temperate forest and the atmosphere. Ecology, 75: 134-150.

Kowalski A.S. and Argüeso D., 2011. Scalar arguments of the mathematical functions defining molecular and turbulent transport of heat and mass in compressible fluids. Tellus, 63B, 1059-1066.

Kutter E., Yi C., Hendrey G., Liu H., Eaton T., and Ni-Meister W., 2017. Recirculation over complex terrain. J. Geophys. Res. Atmos., 122, 6637-6651, doi:10.1002/2016JD026409.

Lenschow D.H., Mann J., and Kristensen L., 1994. How long is long enough when measuring fluxes and other turbulence statistics? J. Atmos. and Oceanic Tech., 11, 661-673.

Leuning R., Zegelin S.J., Jones K., Keith H., and Hughes D., 2008. Measurement of horizontal and vertical advection of $\mathrm{CO}_{2}$ within a forest canopy. Agric. Forest Meteor., 148, 1777-1797.

Mammarella I., Kolari P., Vesala T., and Rinne J., 2007. Determining the contribution of vertical advection to the net ecosystem exchange at Hyytiälä forest, Finland. Tellus, 59B, 900-909.

Marcolla B., Cobbe I., Minerbi S., Montagnani L., and Cescatti A., 2014. Methods and uncertainties in the experimental assessment of horizontal advection. Agric. Forest Meteor., 98-199, 62-71.

McHugh D., Beringer J., Cunningham S.C., Baker P.J., Cavagnaro T.R., Mac Nally R., and Thompson R.M., 2017. Interactions between nocturnal turbulent flux, storage and advection at an "ideal" eucalypt woodland site. Biogeosciences, 14, 3027-3050, https://doi.org/10.5194/ bg-14-3027-2017.

Metzger S., 2018. Surface-atmosphere exchange in a box: Making the control volume a suitable representation for in-situ observations. Agric. Forest Meteor., https://doi.org/ 10.1016/j.agrformet.2017.08.037.
Montagnani L., Manca G., Canepa E., and Georgieva E., 2010. Assessing the method-specific differences in quantification of $\mathrm{CO}_{2}$ advection at three forest sites during the ADVEX campaign. Agric. Forest Meteor., DOI: 10.1016/j. agrformet.2010.01.013.

Montagnani L., Manca G., Canepa E., Georgieva E., Acosta M., Feigenwinter C., Janous D., Kerschbaumer G., Lindroth A., Minach L., Minerbi S., Mölder M., Pavelka M., Seufert G., Zeri M., and Ziegler W., 2009. A new mass conservation approach to the study of $\mathrm{CO}_{2}$ advection in an alpine forest. J. Geophysical Research-Atmospheres, 114, D07306, DOI:10.1029/2008JD010650.

Nappo C.J., Caneill J. ., Furman R.W., Gifford F.A., Kaimal J.C., Kramer M.L., Lockhart T.J., Pendergast M.M., Pielke R.A., Randerson D., Shreffler J.H., and Wyngaard J.C., 1982. The workshop on the representativeness of meteorological observations. June 1981, Boulder, Colorado, Bull. Am. Meteorol. Soc., 63, 761-764.

Nicolini G., Aubinet M., Feigenwinter C., Heinesch B., Lindroth A., Mamadou O., Moderow U., Mölder M., Montagnani L., Rebmann C., and Papale D., 2018. Impact of $\mathrm{CO}_{2}$ storage flux sampling uncertainty on net ecosystem exchange measured by eddy covariance. Agric. Forest Meteor., 248, 228-239, http://dx.doi.org/10.1016/j. agrformet.2017.09.025.

Ohkubo S. and Kosugi Y., 2008. Amplitude and seasonality of storage fluxes for $\mathrm{CO}_{2}$, heat and water vapour in a temperate Japanese cypress forest. Tellus B, 60, 1, DOI: 10.1111/ j.1600-0889.2007.00321.x.

Peltola O., Hensen A., Marchesini L.B., Helfter C., Bosvel F.C., van den Bulk P., Haapanala S., van Huissteden K., Laurila T., Lindroth A., Nemitz E., Röckmann T., Vermeulen A.T., and Mammarella I., 2015. Studying the spatial variability of methane flux with five eddy covariance towers of varying height. Agric. Forest Meteor., 214-215, 456-472.

Raupach M.R., 1988. Canopy Transport Processes, in: Flow and transport in the natural environment (Eds W.L. Steffen, O.T Denmead). Springer, Berlin, Germany.

Rella C.W., Chen H., Andrews A.E., Filges A., Gerbig C., Hatakka J., Karion A., Miles N.L., Richardson S.J., Steinbacher M., Sweeney C., Wastine B., and Zellweger C., 2013. High accuracy measurements of dry mole fractions of carbon dioxide and methane in humid air. Atmos. Meas. Tech., 6, 837-860, 2013, doi:10.5194/amt-6$837-2013$.

Saunders M., Dengel S., Moureaux C., et al., 2018. Assessing the impacts of site characteristics, management, disturbance and lateral fluxes on net ecosystem carbon dynamics at ICOS sites. Int. Agrophys., 32, 457-469.

Siebicke L., Hunner M., and Foken T., 2012. Aspects of $\mathrm{CO}_{2}$ advection measurements. Theor. Appl. Climatol., 109: 109-131.

Siebicke L., Steinfeld G., and Foken T., 2011. $\mathrm{CO}_{2}$-gradient measurements using a parallel multi-analyzer setup. Atmospheric Measurement Techniques, 4(3), 409.

Wang X., Wang C., Guo Q., and Wang J., 2016. Improving the $\mathrm{CO}_{2}$ storage measurements with a single profile system in a tall-dense-canopy temperate forest. Agric. Forest Meteor., 228, 327-338, http://dx.doi.org/10.1016/j.agrformet. 2016.07.020. 
Xu K., Metzger S., and Desai A.R., 2018a. Surface-atmosphere exchange in a box: Space-time resolved storage and net vertical fluxes from tower-based eddy covariance. Agric. Forest Meteorol., 255, 81-91, http://dx.doi.org/10.1016/j. agrformet.2017.10.011.

Xu X., Yi C., Montagnani L., and Kutter E., 2018b. Numerical study of the interplay between thermo-topographic slope flow and synoptic flow on canopy transport processes. Agric. Forest Meteorol., https://doi.org/10.1016/j. agrformet.2017.03.004.

Yang B., Hanson P.J., Riggs J.S., Pallardy S.G., Heuer M., Hosman K.P., Meyers T.P., Wullschleger S.D., and Gu
L.-H., 2007. Biases of $\mathrm{CO}_{2}$ storage in eddy flux measurements in a forest pertinent to vertical configurations of a profile system and $\mathrm{CO}_{2}$ density averaging. J. Geophysical Res., 112, D20123, doi:10.1029/2006JD008243.

Yang P.C., Black T.A., Neuman H.H., Novak M.D., and Blanken P.D., 1999. Spatial and temporal variability of $\mathrm{CO}_{2}$ concentration and flux in a boreal aspen forest. J. Geophysical Res., 104, D22, 27,653-27.

Yi C., Davis K.J., Bakwin P.S., Berger B.W., and Marr L.C., 2000. Influence of advection on measurements of the net ecosystem-atmosphere exchange of $\mathrm{CO}_{2}$ from a very tall tower. J. Geophysical Res., 105, D8, 9991-9999. 